\title{
SAM levels, gene expression of SAM synthetase, methionine synthase and ACC oxidase, and ethylene emission from N. suaveolens flowers
}

\author{
Susanna Roeder - Katharina Dreschler - Markus Wirtz • \\ Simona M. Cristescu · Frans J. M. van Harren • \\ Rüdiger Hell $\cdot$ Birgit Piechulla
}

Received: 24 October 2008/Accepted: 7 April 2009/Published online: 26 April 2009

(c) The Author(s) 2009. This article is published with open access at Springerlink.com

\begin{abstract}
S^{\prime}$ adenosyl-L-methionine (SAM) is a ubiquitous methyl donor and a precursor in the biosynthesis of ethylene, polyamines, biotin, and nicotianamine in plants. Only limited information is available regarding its synthesis (SAM cycle) and its concentrations in plant tissues. The SAM concentrations in flowers of Nicotiana suaveolens were determined during day/night cycles and found to fluctuate rhythmically between 10 and $50 \mathrm{nmol} \mathrm{g}^{-1}$ fresh weight. Troughs of SAM levels were measured in the evening and night, which corresponds to the time when the major floral scent compound, methyl benzoate, is synthesized by a SAM dependent methyltransferase (NsBSMT) and when this enzyme possesses its highest activity. The SAM synthetase (NsSAMS1) and methionine synthase (NsMS1) are enzymes, among others, which are involved in the synthesis and regeneration of SAM. Respective genes were isolated from a $N$. suaveolens petal cDNA library. Transcript accumulation patterns of both SAM regenerating enzymes matched perfectly those of the bifunctional NsBSMT; maximum mRNA accumulations of
\end{abstract}

Electronic supplementary material The online version of this article (doi:10.1007/s11103-009-9490-1) contains supplementary material, which is available to authorized users.

S. Roeder · K. Dreschler $\cdot$ B. Piechulla $(\varangle)$

Department of Biological Sciences, Institute of Biological

Sciences, University of Rostock, Albert-Einstein-Str. 3,

18059 Rostock, Germany

e-mail: birgit.piechulla@uni-rostock.de

S. M. Cristescu · F. J. M. van Harren

Life Science Trace Gas Facility, Radboud University Nijmegen,

Heyendaalweg 135, 6525 AJ Nijmegen, The Netherlands

M. Wirtz $\cdot$ R. Hell

Heidelberg Institute of Plant Sciences, University of Heidelberg, Im Neuenheimer Feld 360, 69120 Heidelberg, Germany
$N s \mathrm{MS} 1$ and NsSAMS1 were attained in the evening. Ethylene, which is synthesized from SAM, reached only low levels of 1-2 ppbv in $N$. suaveolens flowers. It is emitted in a burst at the end of the life span of the flowers, which correlates with the increased expression of the 1-aminocyclopropane-1-carboxylate oxidase (NsACO).

Keywords SAM cycle $\cdot$ SAM synthetase .

Methionine synthase $\cdot$ ACO $\cdot$ Carboxyl methyltransferase . Nicotiana suaveolens $\cdot$ Floral metabolism $\cdot$ SAM level

\author{
Abbreviations \\ SAM $\quad S^{\prime}$ adenosyl-L-methionine \\ SAH $\quad S^{\prime}$ adenosyl-homocysteine \\ Met Methionine \\ ACC 1-Aminocyclopropane-1-carboxylate \\ BSMT Benzoic acid/salicylic acid: $S^{\prime}$ adenosyl-L- \\ methionine carboxyl methyltransferase \\ LD Light/dark \\ MetE Vitamine- $\mathrm{B}_{12}$-independent methionine synthase \\ OMT $O^{\prime}$ methyltransferase \\ NMT $\quad N^{\prime}$ methyltransferase
}

\section{Introduction}

Plants are sessile organisms and therefore use, in addition to other cues, volatile organic compounds (VOCs) as signals for inter- and intraorganismic communication (Piechulla and Pott 2003). VOCs are involved in direct or indirect defence or attraction reactions (Pare and Tumlinson 1999). More than 2,000 volatile compounds are presently known (Knudsen et al. 2006; Dunkel et al. 2009). The majority of these low molecular mass organic compounds 
(molecular masses under 300) is synthesized by three major biosynthetic pathways: the terpenoid, the benzenoid/ phenylpropanoid and the fatty acid pathway. To increase volatility, the compounds are often chemically modified, e.g. methylation reactions catalysed by $O^{\prime}$ methyltransferases result in the formation of esters and ethers. The methyl donor of many transmethylation reactions is $S^{\prime}$ adenosyl-Lmethionine (SAM), resulting in a conserved SAM-binding domain shared by the $O^{\prime}$ methyltransferases, whereas the primary, secondary and tertiary structure of the residual parts of the enzymes are distinct (Kagan and Clarke 1994; Noel et al. 2003; Effmert et al. 2005). A large family of small molecule $O^{\prime}$ methylating methyltransferases (in contrast to protein and nucleic acid methlytransferases) are classified as type I $O^{\prime}$ methyltransferases (OMTs), e.g. eugenol, chavicol, orcinol and furanone OMTs (Wang et al. 1997; Lavid et al. 2002; Wein et al. 2002). The caffeoylCoA OMT involved in lignin formation for example is a member of the type II OMT family (Noel et al. 2003). The type III $O^{\prime}$ methyltransferase comprises a group of NMTs and carboxyl OMTs. Many such carboxyl OMTs are responsible for the formation of the dominant compounds of floral scents, e.g. methyl salicylate and methyl benzoate (Effmert et al. 2005), whereas others are involved in the synthesis of methyl jasmonate, methyl farnesoate or methyl cinnamate (Seo et al. 2001; Yang et al. 2005; Kapteyn et al. 2007)

Besides being an important substrate for many carbon metabolite methyltransferases, SAM also plays numerous other roles in the development of a plant. It is the major methyl group donor in transmethylation reactions of DNA, RNA, proteins, and lipids, and is an intermediate in the biosynthesis of polyamines, nicotianamine, biotin and ethylene (FigS1). Ethylene biosynthesis is performed through the activity of 1-aminocyclopropane-1-carboxylate (ACC) synthase and ACO (ACC oxidase) in plants, the spermidine and spermine biosynthesis through the activity of the SAM decarboxylase, the synthesis of nicotianamine through the activity of nicotianamine synthase and the biotin biosynthesis through the activity of 7,8-diaminopelargonic acid aminotransferase. SAM can have regulatory functions since it behaves as an allosteric activator of threonine synthase (Ravanel et al. 1998 and references therein). Recent interest has focused on the SAM-dependent cytosine methylation reactions of DNA, because this leads to altered plant morphology and induces homeotic alterations in flower organs. All these metabolic reactions are considered important for the development and growth of the plant.

In this study, we specifically focussed on the metabolism of SAM in flowers. N. suaveolens flowers were selected due to our previous studies on the $O^{\prime}$ methyltransferase (BSMT), which synthesizes methylated scent compounds for floral emission. The emission of scent compounds is rhythmic with high levels at night (nocturnal emission) (Effmert et al. 2008). The highest methyl benzoate emission occurs in the first and second night after flower opening suggesting a preferred nocturnal requirement of SAM. Flowers of 5-6 days of age (senescence) no longer emit methyl benzoate, so that presumably SAM is not further needed for the synthesis of methylated scent compounds. However, during senescence, SAM might be required for the production of ethylene.

The metabolic regeneration of SAM through the SAM cycle comprises four reactions: (1) the demethylation of SAM into $S^{\prime}$ adenosyl-homocysteine (SAH) by the action of methyltransferases, (2) the hydrolysis of SAH to homocysteine by homocysteine hydrolase, (3) the methylation of homocysteine to methionine by methionine synthase, and (4) the adenylation of methionine to SAM by SAM synthetase (Fig. S1).

There is a lack of knowledge regarding SAM concentrations in plant tissues, which encouraged us to determine SAM levels in $N$. suaveolens flowers, and to correlate them to the expression profiles of genes involved in SAM synthesis (methionine synthase, SAM synthetase) and SAM consumption (BSMT: Pott et al. 2004; Effmert et al. 2005, 2008; and ACC synthase). Furthermore, the precise nocturnal emission of methylated compounds from flowers inspired us to temporally analyse the expression of respective genes.

\section{Materials and methods}

\section{Plant material and plant growth}

Nicotiana suaveolens plants were grown on vermiculite (Deutsche Vermiculite Dämmstoffe $\mathrm{GmbH}$, Sprockhövel, Germany) in growth chambers under long day conditions $\left(16 \mathrm{~h}\right.$ illumination at $100 \mu \mathrm{E} \mathrm{m}^{-2} \mathrm{~s}^{-1}$ and $22^{\circ} \mathrm{C}, 8 \mathrm{~h}$ darkness at $18^{\circ} \mathrm{C}$ ). Plants were watered with Hoaglands solution. To determine the flower age at the time of harvest, flowers were marked when flower buds opened (=day 1).

For cDNA library construction, petals were harvested from approximately 3-month-old plants at intervals of $3 \mathrm{~h}$ over a period of 2 days (1st and 2nd day after flower opening) and then pooled.

To determine the transcript levels in the various organs and tissues, plant material (corolla lobe and corolla tube, stamen/stigma, sepals, stems, leaves, roots) were harvested at $6 \mathrm{pm}$ from 3-month-old plants, frozen in liquid nitrogen and stored at $-70^{\circ} \mathrm{C}$.

In order to examine the expression profiles of plants grown under LD cycles ( $16 \mathrm{~h}$ light/ $8 \mathrm{~h}$ darkness; $10 \mathrm{pm}$ to 6 am darkness), four flowers (approximately $460 \mathrm{mg}$ fresh 
weight) were harvested at indicated time points at day 1-6 after flower opening. At days 5 and 6, the flowers showed obvious signs of senescence (petal wilting and appearance of a brown colour).

To determine SAM levels, tissue was harvested from two independent plant sets: (1) 13-week-old plants, and (2) 16-week-old plants. From each plant set, circa $200 \mathrm{mg}$ petal tissue from three flowers was harvested from the $1 \mathrm{st}$ to the 6th day after flower opening at $7 \mathrm{am}, 11 \mathrm{am}, 3 \mathrm{pm}$, $7 \mathrm{pm}, 11 \mathrm{pm}$ and 3 am.

For ethylene emission measurements, plants were grown in the greenhouse at the University of Rostock for 2-3 months. The flowering plants were then transported to the Radboud University in Nijmegen and plants could acclimate (16 h light, $8 \mathrm{~h}$ darkness in a growth chamber) for 3 days prior to ethylene experiments.

RNA isolations and northern blot analysis

RNA was isolated according to Cheng and Seemann (1998) when the RNA was used for Northern blot analysis. Samples of $400 \mathrm{mg}$ of frozen plant material were ground with liquid nitrogen and extraction buffer (50\% guanidinium isothiocyanate, $0.5 \% \mathrm{~N}$-lauryl sarcosine, $26 \mathrm{mM}$ sodium citrate $\mathrm{pH} 7.0,0.7 \% \quad \beta$-mercaptoethanol), and extracted with phenol. RNA was precipitated and resuspended in RNase free $\mathrm{ddH}_{2} \mathrm{O}$, and stored at $-70^{\circ} \mathrm{C}$.

Aliquots of $5 \mu \mathrm{g}$ total RNA were separated by formaldehyde denaturing gel electrophoresis and transferred to nylon membranes (Roche Diagnostics GmbH, Mannheim, Germany). The RNA was fixed to the membrane by UV crosslinking. The probes (SAM synthetase $1487 \mathrm{bp}$, methionine synthase $500 \mathrm{bp}$, ACO $700 \mathrm{bp}$, 18SrDNA $340 \mathrm{bp}$ ) were labelled with digoxygenin-11-dUTP according to the protocol of the manufacturer (Roche Molecular Biochemicals, Mannheim, Germany). Hybridization and detection with CDP-Star was performed according to the manufacturer (Roche Molecular Biochemicals, Mannheim, Germany). The chemiluminescence signal was detected and quantified with the Luminescent Image Analyzer LAS1000 and Image gauge software (Fujifilm, Tokyo, Japan). Transcript levels were normalised to rRNA levels and the mRNA/rRNA ratios were calculated. The sample with the highest expression level within a given experiment was set to $100 \%$. The results are based on hybridizations of two independent RNA preparations.

RNA was extracted according to Chang et al. (1993) when used for the construction of the cDNA library because this method did not include a phenol extraction step. Frozen plant material $(0.5-1 \mathrm{~g})$ was ground in liquid nitrogen and extraction buffer (2\% CTAB hexadecyltrimethyl ammonium bromide, $2 \%$ PVP polyvinyl pyrrolidone K40, 100 mM Tris-HCl, pH8.0, 25 mM EDTA, 2 M
$\mathrm{NaCl}, 2.67 \% \quad \beta$-mercaptoethanol). The RNA was resuspended in $\mathrm{RNase}$-free $\mathrm{ddH}_{2} \mathrm{O}$ and stored at $-70^{\circ} \mathrm{C}$ (yield: $1.15 \mathrm{mg}$ RNA/3.6 g petal fresh weight).

Poly $\mathrm{A}^{+}$RNA was isolated from flower total RNA by using the oligotex-dT mRNA kit (Qiagen, Hilden, Germany). Purification was performed according to the manufacturer's protocol, except that the purification on the column was repeated twice $(500 \mu \mathrm{g}$ total RNA yielded circa $10 \mu \mathrm{g}$ poly $\mathrm{A}^{+}$RNA).

cDNA libray construction and cDNA isolation

To synthesize cDNA, a ZAP Express ${ }^{\circledR}$ cDNA Synthesis Kit (Stratagene, Amsterdam, The Netherlands) was used. PolyA ${ }^{+}$RNA $(5 \mu \mathrm{g})$ was used for the first strand synthesis. The cDNA preparation was separated on a $1 \mathrm{ml}$ Sepharose $\mathrm{CL}^{\circledR}-2 \mathrm{~B}$ column (STE buffer, 0.1 M sodium chloride, $20 \mathrm{mM}$ Tris- $\mathrm{HCl} \mathrm{pH} 7.5,10 \mathrm{mM}$ EDTA) and fractions of three drops were taken. Fractions were extracted with phenol/chloroform $(1: 1 ; \mathrm{v}: \mathrm{v})$ and precipitated with ethanol over-night (centrifugation, $60 \mathrm{~min}, 4^{\circ} \mathrm{C}, 15,000 \mathrm{~g}$ ). DNA (200 ng equivalent to $1.5-3.5 \mathrm{kbp}$ ) was ligated into $\mathrm{pBK}$ CMV and transformed into E.coli XL-Blue MRF' according to the manufacturer's protocol. For packaging, the ZAP Express $^{\circledR}$ Gigapack $^{\circledR}$ III Gold Cloning Kit was used and the experiment was performed exactly as described in the instruction manual. The titre of the primary library was $5 \times 10^{5} \mathrm{pfu} / \mathrm{ml}$. This library was amplified $\left(1 \times 10^{8} \mathrm{pfu} /\right.$ $\mathrm{ml}$ ) in phages to reveal a stable cDNA library, which was stored in $1 \mathrm{ml}$ aliquots at $-70^{\circ} \mathrm{C}$, after addition of dimethylsulphoxide to a final concentration of $7 \%$.

cDNA library aliquots of approximately 20,000 pfu per plate were incubated with E.coli host cells in top agar for 8 h. Nylon membranes (Roche Diagnostics, Mannheim, Germany) were placed onto the agar for 2 or $4 \mathrm{~min}$ and filter lifts and hybridization was performed according to the DIG System User's Guide for Filter Hybridization (Roche Diagnostics, Mannheim, Germany). A 483 bp fragment of a potential monoterpene synthase of $N$. suaveolens was used as a probe, and obtained clones were further investigated.

The excision of the $\mathrm{pBK}$ CMV phagemid was performed with the E.coli strain XLOR and the helper phage R 408 (Stratagene, Amsterdam, The Netherlands) and the resulting bacterial colonies were stored at $-70^{\circ} \mathrm{C}$.

Gene sequencing and tree construction

cDNAs were sequenced using the LI-COR DNA-Sequencer (MWG-Biotech, Ebersberg, Germany) and professional sequencing service (AGOWA, Berlin, Germany). Complete translated protein sequences were compared with the sequences present in the NCBI data bank by using Clustal 
W/Align X (Altschul et al. 1990). Phylogenetic trees were generated by using PAUP 4.0 (b10) and visualized with TreeView. Sequences were submitted to the EMBL databank; accession numbers are as follows: methionine synthase DQ 984138, SAM synthetase DQ 984137, SAH hydrolase DQ 984135, ACO DQ 984136.

\section{Determination of SAM levels}

Approximately, $200 \mathrm{mg}$ petal tissue was harvested at specific time points during plant development and during the day (see: plant growth) and immediately frozen in liquid nitrogen for storage at $-80^{\circ} \mathrm{C}$. The tissue was powdered in liquid nitrogen and extracted at $4{ }^{\circ} \mathrm{C}$ for 15 min with $0.5 \mathrm{ml}$ of $0.1 \mathrm{M} \mathrm{HCl}$. The plant homogenate was centrifuged twice for $10 \mathrm{~min}$ at $4^{\circ} \mathrm{C}$ and $16,400 \mathrm{~g}$ to remove cell debris and membranes. The resulting supernatant was used for derivatization of SAM with chloroacetaldehyde as described in Rzewuski et al. (2007). SAM was separated from other adenosine compounds by reverse phase chromatography and quantified by external standards according to Haink and Deussen (2003). All chromatograms were recorded and processed with the Millenium ${ }^{32}$ software (Waters).

\section{Determination of ethylene emission}

Ethylene measurements were performed at the Radboud University Nijmegen by using a sensitive laser-based ethylene detector (type ETD-300, Sensor Sense B.·V., Nijmegen, the Netherlands) in combination with a gas handling system. The ETD-300 detector is based on laser photoacoustic spectroscopy, a well-established method successfully used in many applications in Life Science when traditional methods, such as gas chromatography, cannot be employed because of lack of sensitivity and time-consuming preconcentration steps (Harren and Reuss 1997; Te Lintel Hekkert et al. 1998, Cristescu et al. 2002). The detection limit of the ETD-300 is about $300 \mathrm{pptv}$ $\left(\right.$ pptv $=$ parts-per-trillion volume, $\left.1: 10^{12}\right)$ for on-line ethylene within a $5 \mathrm{~s}$ time-scale. Gas handling was performed by a valve control box (type VC-6, Sensor Sense B. V., Nijmegen, the Netherlands) designed for measuring up to six sampling cuvettes per experiment. Emission of ethylene from individual flowers of $N$. suaveolens was measured in real time over a 7-day period. Single flowers remained attached to the plants and, at the day of anthesis, were enclosed into specially designed glass cuvettes (each $25 \mathrm{ml}$ volume), sealed around the stem with a harmless flexible clay Terostat-IX (Henkel, Düsseldorf, Gemany) and continuously flushed with air. Through the valve control box, ethylene was transported to the ETD-300 alternately, at intervals of $30 \mathrm{~min}$ for each cuvette and at controlled flow rates of $2 \mathrm{~L} \mathrm{~h}^{-1}$, thus preventing accumulation effects. In order to obtain a good overview, the average value of ethylene production from the last $20 \mathrm{~min}$ out of the $30 \mathrm{~min}$ of sampling was displayed, indicating the ethylene emission rate every $2 \mathrm{~h}$.

\section{Results}

Developmental changes of SAM levels in $N$. suaveolens flower tissue

A detailed analysis of SAM concentrations in N. suaveolens flowers was performed. Petals of defined developmental stages and at certain time points during the day were harvested, since it was our interest to determine the daily changes of SAM levels during flower development. In addition, the entire experiment was independently replicated to cover the impact of biological variability caused by environmental factors. Each sample comprised petal tissue from three individual flowers. The amount of SAM in petals of $N$. suaveolens was $30 \mathrm{nmol} \mathrm{SAM} \mathrm{g}^{-1}$ fresh weight on average, which is a comparable value of SAM found in rosette leaves of Arabidopsis thaliana $\left(10 \mathrm{nmol} \mathrm{g}^{-1}\right.$ fresh weight, Bürstenbinder et al. 2007). Throughout the day, the SAM levels varied rhythmically in 1- to 4-day-old petals (Fig. 1). SAM accumulated to higher levels before noon (50 nmol $\mathrm{g}^{-1}$ fresh weight), and lower levels were present in the later afternoon and during the night (10 nmol g ${ }^{-1}$ fresh weight). In 5-to 6-day-old flowers, the rhythm attenuated.

Cloning of cDNAs encoding methionine synthase, SAM synthetase and ACC oxidase from $N$. suaveolens flowers

A cDNA library from $N$. suaveolens petals was constructed with the aim to isolate flower-specific cDNAs of the enzymes of the SAM cycle and related biosynthetic pathways. We successfully isolated cDNAs encoding methionine synthase (NsMS1), SAM synthetase (NsSAMS1) and ACC oxidase (NsACO) (Figs. S1, S2).

The methionine synthase cDNA of $N$. suaveolens with a length of 2,295 nucleotides (765 amino acids) was the only one isolated from the flower library. A BLAST-Search revealed $95 \%$ sequence identity with a homologous gene from Solanum tuberosum and the phylogenetic tree (neighbour-joining method), clustered the gene with those from Catharanthus roseus and Solanum tuberosum having the same origin as the cluster of monocotyledonous species (Fig. 2A). More than 1,350 methionine synthase sequences are compiled in the data bank, with at least 1,000 from prokaryotes and 72 sequences from 16 plants species. The 
Fig. 1 Detemination of SAM levels in flowers of N. suaveolens. Petals of three $N$. suaveolens flowers of specific developmental stage (1-6 days after anthesis) were harvested at 4-hour intervals (3 am, 7 am, 11 am, 3 pm, 7 pm, $11 \mathrm{pm})$ and immediately frozen in liquid nitrogen. SAM was extracted and analysed by HPLC to determine the SAM content in the samples. Two independent experiments were performed $(n=2)$

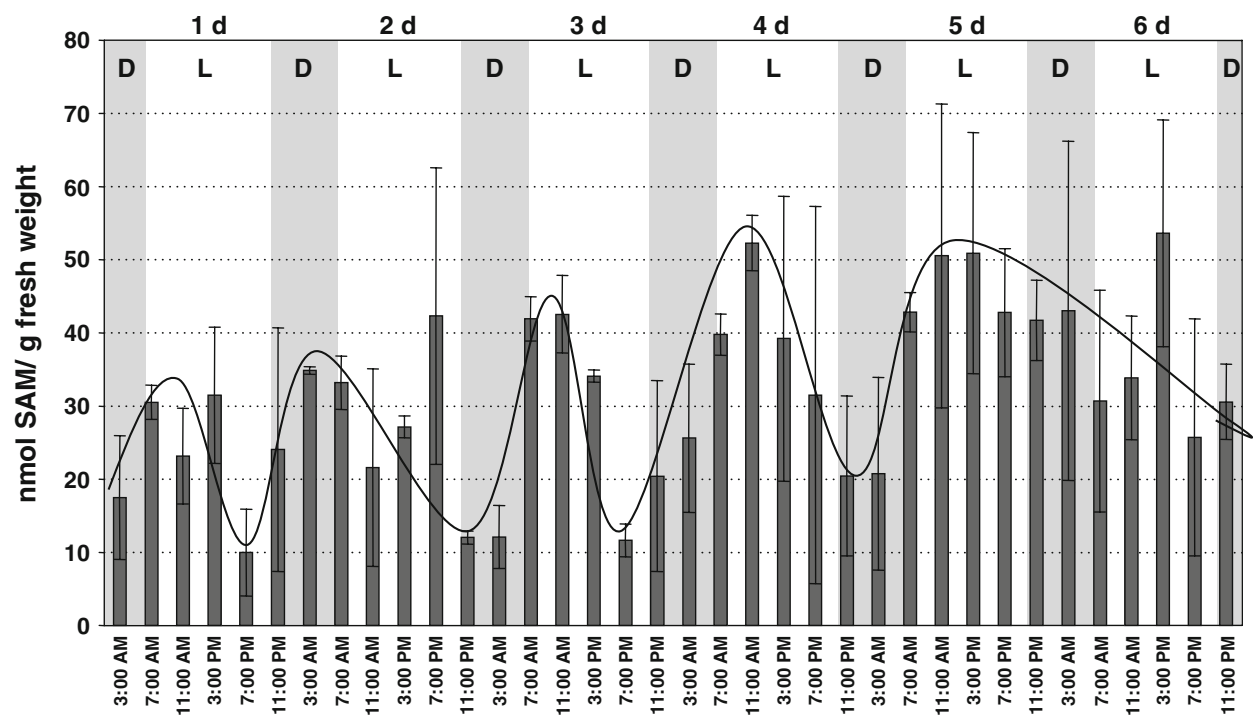

time isolated gene was probably related to the vitamin- $\mathrm{B}_{12^{-}}$ independent enzyme $M e t E$ found in fungi, plants and other organisms, in contrast to the cobalamin-dependent enzyme $M e t H$, additionally present in bacteria (Eichel et al. 1995; Eckermann et al. 2000). Eleven of the Met E genes were aligned and the gene sequences exhibited high conservation, particularly in the second half of the enzyme (Fig. S2A). A PEST-like sequence (ELGPEVNFSYASHKA), previously identified in proteins with short half-life times, was present in a variety of plant genes including the methionine synthase and $S^{\prime}$ adenosyl-methionine decarboxylases (Zeh et al. 2002 and references therein). A conserved motif present in all vitamin- $\mathrm{B}_{12}$-independent methionine synthases was found in the C-terminal sequence of the $N$. suaveolens enzyme (WVNPDCGLKT, amino acid positions 728-738). Analysis with the ChloroP and TargetP programs indicated no transit peptide suggesting a localization of the enzyme in the cytosol.

The SAM synthetase gene of $N$. suaveolens with a length of 1,173 nucleotides (391 amino acids) was the only of such sequence isolated from the floral library. The BLAST Search revealed more than $96 \%$ sequence identity with the respective genes from various Solanaceae species, and the phylogenetic tree construction supported the result (Fig. 2B). Interestingly, a second protein from S. tuberosum appeared in a different sub-cluster, and similarly the three SAM synthetases from Catharanthus roseus also cluster separately, as did the two Brassicaeae sequences that presented isolated sister groups. More than 1,570 SAM synthetase sequences are filed in the data bank, 1,195 from prokaryots and 105 sequences from 27 plant species. Fifteen of the corresponding proteins were aligned and exhibited high conservation throughout the whole sequence (Fig. S2B). Two conserved motifs (GAGDQG and
GGGAFSGKD) present in all plant SAM synthetases have been found (Kagan and Clarke 1994; Lindroth et al. 2001). The hexapeptide and glycine-rich nonapeptide motifs (amino acids 119-124 and 266-174, respectively) constituting a P-loop-like sequence are thought to be involved in binding the adenine moiety or the triphosphate of ATP, respectively (Horikawa et al. 1990; Lindroth et al. 2001). The absence of a transit peptide suggested the localization of the enzyme in the cytosol.

$S^{\prime}$ adenosyl methionine (SAM) is a precursor of ethylene synthesis and therefore converted to 1-aminocyclopropane1-carboxylic acid (ACC) by ACC synthase and then further metabolised to ethylene by the enzyme ACO (ACC oxidase) (Fig. S1). Therefore, this biosynthetic pathway is directly connected to the SAM cycle and its regulation was part of our research interest. A single ACO cDNA (open reading frame of 924 nucleotides) was isolated from the flower cDNA library of $N$. suaveolens and the translated sequence was compared with known sequences in the data bank. The amino acid sequence alignment revealed high conservation in the middle and C-terminal part of the enzymes (Fig. S2C). The analysis of the phylogenetic relationship revealed a separation of homologous proteins from different Nicotiana species in sister groups rather than in a monophyletic cluster (Fig. 2C). Analysis with the ChloroP and TargetP programs indicated a cytosolic localization of the enzyme.

Expression of SAM synthetase, methionine synthase and ACC oxidase in various plant organs and tissues

The SAM cycle is a fundamental metabolic pathway providing cells and tissues with SAM, methionine and related metabolites. Up to now, only a few investigations have 
(A)

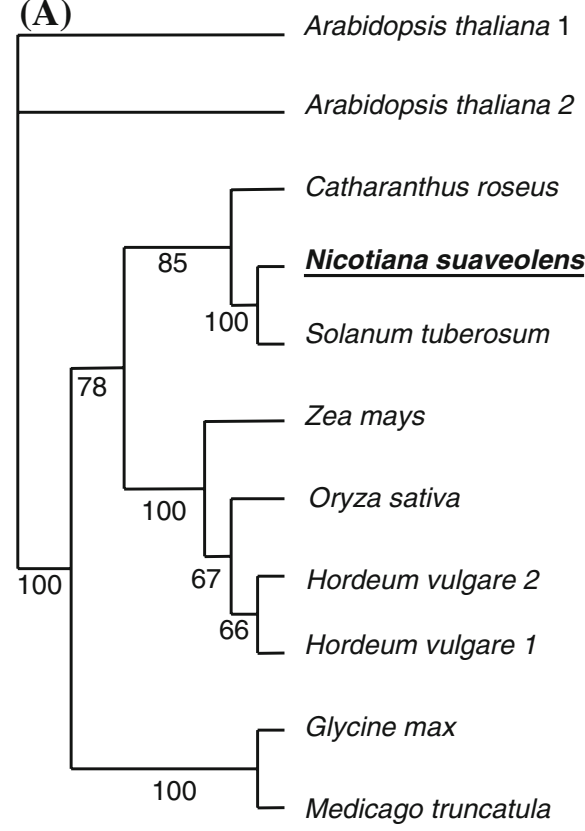

(B)

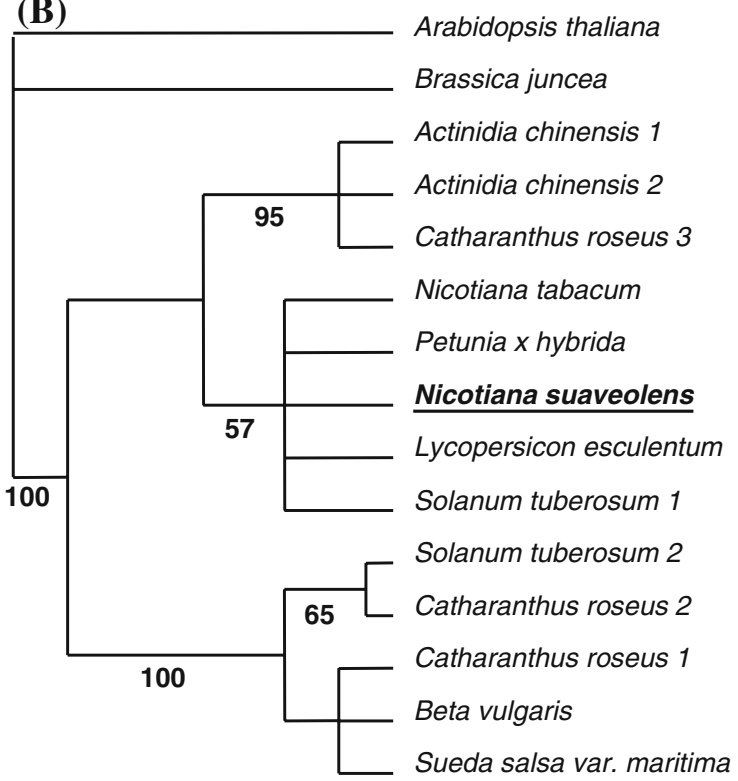

(C)

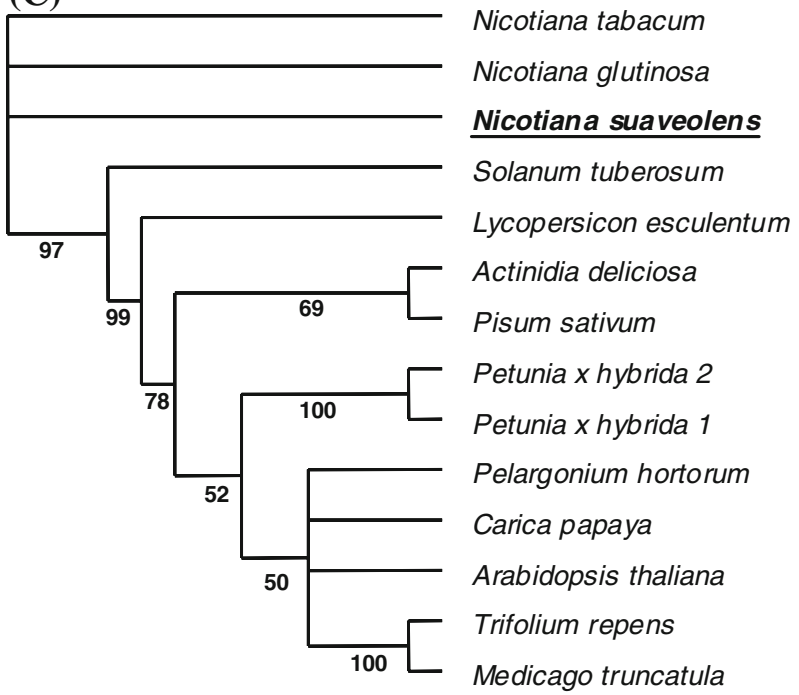

Fig. 2 Phylogentic relationships of methionine synthase, SAM synthetase and ACC oxidase genes from $N$. suaveolens. Unrooted neighbour-joining phylogenetic trees based on amino acid sequence similarities. Trees were created with PAUP (version 4.0b10) and displayed by using TreeView. Gaps in the alignments (Clustal W) were removed for analysis. Bootstrap values below $50 \%$ were not included (1,000 replicates). Symbols 1-4 indicate conserved motifs. (A) methionine synthase: Arabidopsis thaliana (1:AAK 64167, 2:AAN 31838), Catharanthus roseus (CAA 58474), Glycine max (AAQ 08403), Hordeum vulgare (1:BAD 34660, 2:BAD 34661), Medicago truncatula (ABE 84165), Nicotiana suaveolens (DQ 984138), Oryza sativa (ABA 99427) Solanum tuberosum (AAF 74983), Zea mays (AAL 33589). (B) SAM synthetase: Actinidia chinensis (1:AAA 81378, 2:P 50302),
Arabidopsis thaliana (NP 1811225), Beta vulgaris (BAE 07180), Brassica juncea (AAK 71234), Catharanthus roseus (1:CAA 95856, 2:CAA 95857, 3:CAA 95858), Lycopersicon esculentum (CAA 80867), Nicotiana tabacum (AAF 42974), Nicotiana suaveolens (DQ984137), Petunia hybrida (CAA 57696), Solanum tuberosum (1:ABB 02634, 2:ABB 29942), Sueda salsa var. mariti. (C) ACC oxidase: Actinidia deliciosa (BAA 21541), Arabidopsis thaliana (AC 27484), Caprica papaya (AAL 78058), Lycopersicon esculentum (BAA 34924), Medicago truncatula (AAL 35971), Nicotiana glutinosa (AAA 99793), Nicotiana suaveolens (DQ 984136), Nicotiana tabacum (CAA 58232), Pelargonium hortorum (AAC 48977), Petunia hybrida (1:Q08508, 2:Q08506), Pisum sativum (P 31239), Solanum tuberosum (AAK 68076), Trifolium repens (AAD 28197) 
shown the expression of SAM cycle genes in leaves, while no information is available for floral tissues. The isolated SAM cycle genes provide now a good opportunity to study this metabolic pathway in flowers. Gene probes were hybridised to total RNA preparations obtained from 3-monthold plants and tissues harvested at $6 \mathrm{pm}$. This harvest time point was chosen because preliminary experiments revealed the highest SAM synthetase and methionine synthase expression levels at this time of the day. Northern blots were hybridised with the NsMS1, NsSAMS1 and NsACO probes and examples of the expression levels of the 3000-, 1400- and 1200-nucleotide-long mRNAs, respectively, are shown in Fig. S3. The highest mRNA accumulations of the NsMS1 and NsSAMS1 genes were found in the tissue of petal lobes $(=100 \%)$ followed by elevated levels in the stigma/styles and stems (Fig. 3). mRNA levels below $20 \%$ were measured in the other floral organs, such as stamens, petal tubes, and sepals and in green leaves and roots. NsACO was highly expressed in petal lobe tissue, and transcripts were also present in the stigma/style, petal tubes and stems, mRNA levels were low in other vegetative tissues (leaves and roots). It is remarkable that in the plants grown under these conditions, the highest expressions of all SAM cycle genes ( $N s$ MS1, NsSAMS1) were detectable in the tissue of petal lobes.

To determine the gene expression levels at different time points during flower development and at different daily time points, petals were collected in $3 \mathrm{~h}$ intervals from the 1st to 6th day after $N$. suaveolens flower opening and the RNA was isolated and hybridised with the NsMS1, NsSAMS1 and NsACO probes. Examples of the expression of the NsMS1 and NsSAMS1 genes are exemplarily shown in Fig. S4. The quantitative analysis revealed simultaneous oscillations from the 1st to the 6th day of flowering for the NsMS1 and NsSAMS1 (Fig. 4A, B). The expression maxima were in the late afternoon/early evening and possess a typical nocturnal expression pattern. The methionine synthase transcripts reached their highest amplitudes in 2- and 3-day-old flowers and, thereafter, the amplitude decreased slowly during flower senescense. The SAM synthetase mRNA oscillations varied around $60-80 \%$, with the maximum amplitude being determined on day 5, whereas in senescent flowers (day 6), SAM synthetase transcript levels decreased.

It is interesting to note that the mRNA oscillation profiles of $N s$ MS1 and NsSAMS1 were very similar regarding period length, amplitude, and time point of maxima and minima suggesting a simultaneous and perhaps coordinated regulation of expression. These mRNA accumulation patterns matched the pattern of the SAM utilizing enzyme, carboxyl methyltransferase (BSMT) (Effmert et al. 2005, 2008), which could suggest that, on a daily basis, SAM synthesis and SAM consumption is synchronised in N. suaveolens flowers. The amplitude of the transcript pattern of the $N s \mathrm{ACO}$ (Figs. S4C and 4C) is altered compared to NsMS1 and NsSAMS1, suggesting that cues other than those for NsMS1 and NsSAMS1 are involved in its regulation.

\section{Ethylene emission from $N$. suaveolens flowers}

During the synthesis of ethylene, SAM is the precursor that is transformed by ACC synthase and ACC oxidase (ACO). Although ACC synthase is usually the rate-limiting step in ethylene biosynthesis, we have investigated the expression level of ACO, since it is the final enzyme in the pathway that produces ethylene.

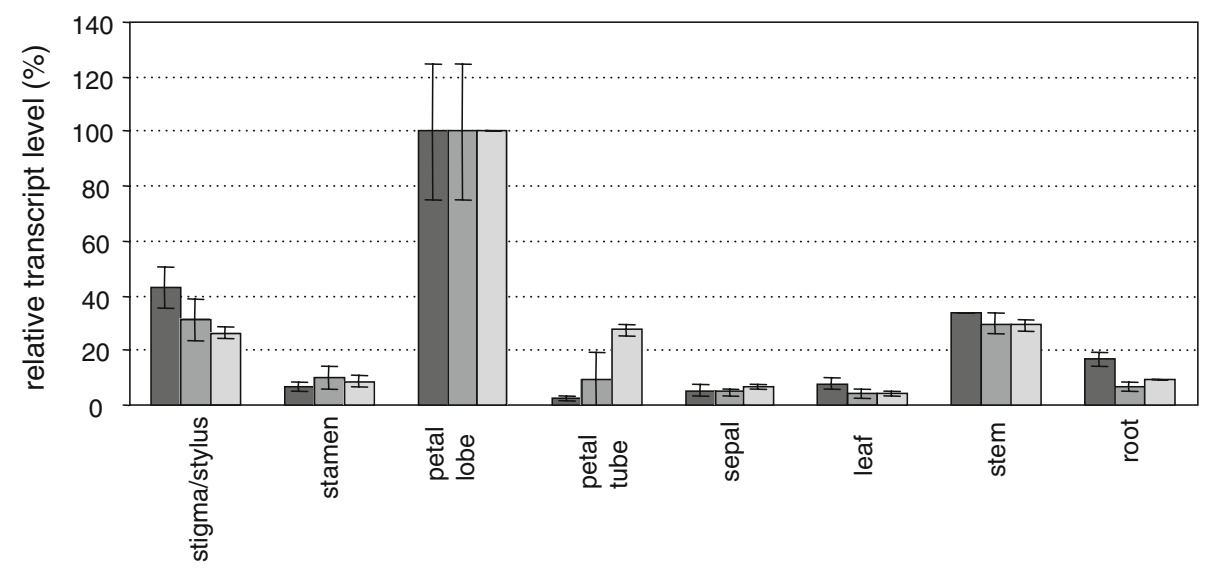

Fig. 3 RNA expression of methionine synthase, SAM synthetase and ACC oxidase in different organs of $N$. suaveolens. Plant tissues (petal lobes, stigmas, stamens, petal tubes, sepals, leaves, stems, roots) were harvested at $6 \mathrm{pm}$ from 3-month-old plants. RNA was isolated and $5 \mu \mathrm{g}$ of total RNA was separated on denaturing agarose gels. RNA was blotted and hybridised with $N s$ SAMS1, NsMS1 and NsACO probes (Fig. S3). Blots were rehybridized with $18 \mathrm{~S}$ rDNA probe to allow normalization. The quantification was based on two independent experiments and duplicated Northern blots. Highest expression levels were set at $100 \%$ and relative transcript levels were calculated, $\mathrm{SE}$ is indicated $(n=4)$. Black column: methionine synthase; grey column: SAM synthetase, light grey column: ACC oxidase 
(A)

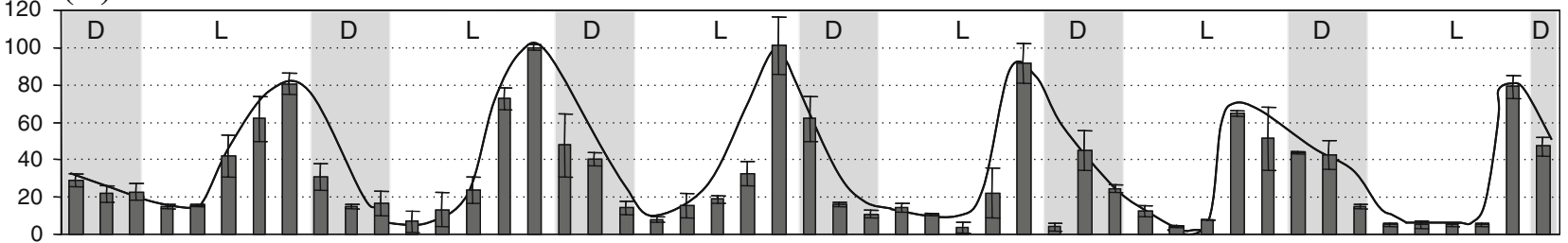

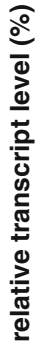

(B)
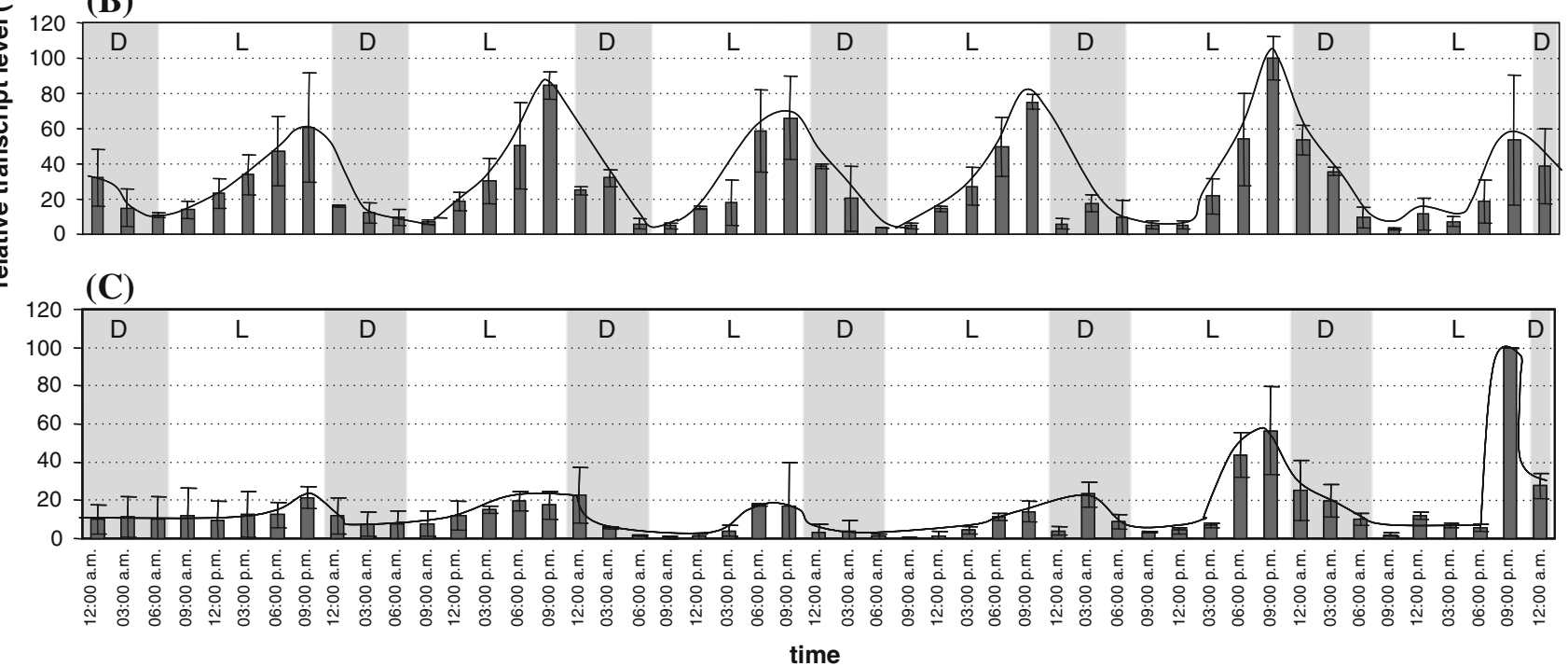

Fig. 4 RNA expression profile of methionine synthase, SAM synthetase and ACC oxidase of $N$. suaveolens at different times during the day and during flower development. Plants were grown under $16 \mathrm{~h}$ light $(\mathrm{L})$ and $8 \mathrm{~h}$ darkness (D; $10 \mathrm{pm}$ to $6 \mathrm{am}$ ) (details of growing conditions are given in $\mathrm{M}$ and $\mathrm{M}$ ). Petals of $N$. suaveolens were harvested at indicated time points at six consecutive days after flower opening. RNA was isolated and $5 \mu \mathrm{g}$ of total RNA was separated on denaturing agarose

The expression profile of $N s$ ACO 1-6 days after anthesis was investigated in petals (Figs. S4C and 4C). Low mRNA levels were present in 1- to 4-day-old flowers and the mRNA levels seemed to accumulate rhythmically, although the amplitudes were small. Oscillations with high amplitudes were detected in the older flowers (day 5 and 6). The maxima of the amplitudes were always reached at the end of the light phase/beginning of darkness (nocturnal expression pattern). To correlate the NsACO expression to ethylene production, individual flowers (attached to the plant) were transferred into specialised glass cuvettes. The emitted ethylene was continuously monitored with an ETD-300 ethylene detector. All flowers exhibited individual emission profiles, three of them being depicted in Fig. 5. Little ethylene was detected in young flowers, whereas in older flowers, a single peak of ethylene emission was observed. The monitored ethylene concentration was in general low, with maximum levels of 1-2 ppbv. The maximum of the peaks were always reached in less than 1 day (in the afternoon and night) and thereafter the levels decreased rapidly. Ethylene emission correlated with the gels. RNA was blotted and hybridised with NsSAMS1, NsMS1 and NsACO probes (Fig. S4). Blots were rehybridized with $18 \mathrm{~S}$ rDNA probe to allow normalisation. The quantification was based on two independent experiments and duplicated Northern blots, highest expression levels were set at $100 \%$ and relative transcript levels were calculated, SE is indicated $(n=4)$. (A) methionine synthase; (B) SAM synthetase; (C) ACC oxidase

occurence of senescence signs at the flower (wilting and appearance of a brown colour). Instead of continuous ethylene oscillations as expected from the ACO expression pattern (Fig. 4C) a single ethylene burst was observed for each individual flower (Fig. 5). This discrepancy might be due to the fact that mRNA was isolated from pooled petals from different flowers, whereas ethylene emission was analysed with individual flowers.

\section{Discussion}

$S^{\prime}$ adenosyl-L-methionine (SAM) is an important biological methyl donor involved in the methylation of many cellular compounds and volatiles and a precursor for the synthesis of metabolites, such as ethylene, polyamines, nicotianamine and biotin. At present, little is known about the concentrations of SAM in plant tissues and, indeed, no information was available for petals. The SAM levels in petals of Nicotiana suaveolens oscillate during the day in the flowers, low levels of ca. $10 \mathrm{nmol} \mathrm{g}^{-1}$ fresh weight 


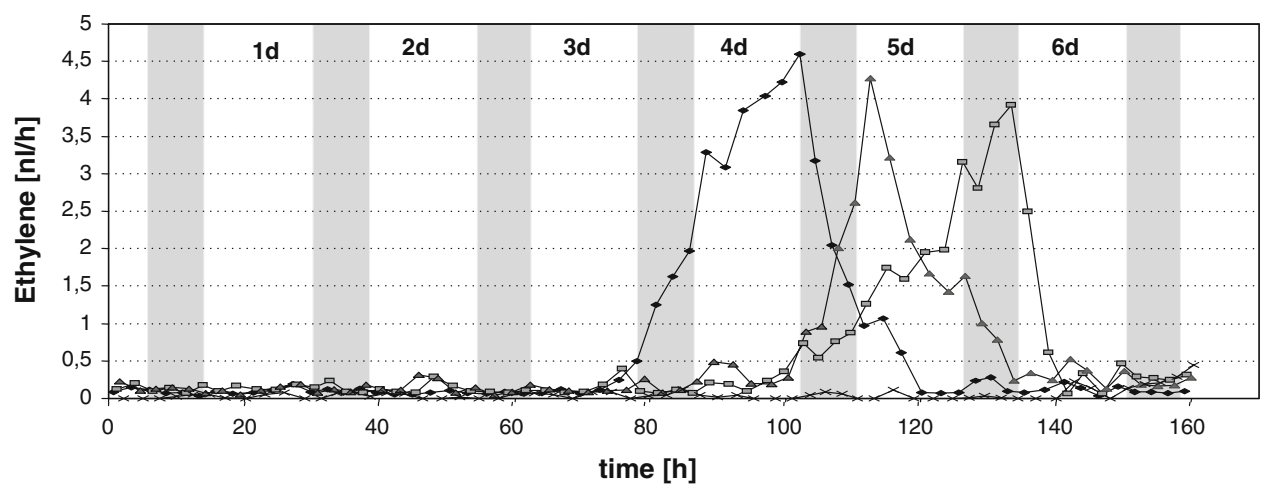

Fig. 5 Ethylene emission from $N$. suaveolens flowers. The emission of ethylene of individual flowers was determined during flower development. Flowers were trapped in special glass cuvettes and sealed. Ethylene was photoacustically analysed and concentrations

were present in the evening ( $7 \mathrm{pm}$ and $11 \mathrm{pm})$ and up to $50 \mathrm{nmol} \mathrm{SAM} \mathrm{g}{ }^{-1}$ fresh weight at the other time points during the day (Fig. 1). The expression of the isolated genes of the SAM cycle, the NsSAMS and NsMS, oscillate during the day (Fig. 4). Their accumulation patterns matched the SAM level fluctuations. The ACC oxidase (NsACO) mRNAs also accumulate rhythmically during flower development. The amplitudes significantly increase during flower senescence, which correlates with the boosted emission of ethylene of individual flowers (Fig. 5).

In order to study the relationship of methyl donor synthesis and utilisation in $N$. suaveolens flowers, the characteristic nocturnal pattern of transcript levels and enzyme activities of the previously isolated flower-specific bifunctional benzoate/salicylate methyltransferase (NsBSMT, Pott et al. 2004; Effmert et al. 2005, 2008) was compared with the expression patterns of the newly isolated SAM cycle enzymes methionine synthase ( $N s \mathrm{MS} 1)$ and SAM synthetase (NsSAMS1). Their similar rhythmic accumulation patterns strongly support a synchronised regulation of expression (Fig. 4). Once the $N s B S M T, N s M S 1$, and $N s S A M S 1$ mRNA levels or the methyl benzoate emission have reached their maximum at night, the SAM levels in $N$. suaveolens flowers drop to low levels suggesting that the troughs of SAM levels can result from the utilisation of SAM during the methylation of scent compounds. Although our current knowledge of SAM cycle gene expression is still rudimentary, the presented experiments show that a precise temporal regulation of gene expression of SAM synthesizing and utilizing reactions is realised in $N$. suaveolens flowers.

With regard to the cellular concentrations of SAM and SAH in plants, only limited data are presently available. In early investigations, Giovanelli et al. (1985) demonstrated that more than $90 \%$ of SAM could be used for transmethylation reactions in Lemna pausicostata. Only recently, $10 \mathrm{nmol} \mathrm{SAM} \mathrm{g}{ }^{-1}$ fresh weight was determined in Arabidopsis thaliana rosette leaves (Bürstenbinder et al. 2007), were determined using a $\mathrm{CO}_{2}$ laser. Plants were kept in a growth chamber (16 h light, $8 \mathrm{~h}$ darkness). Three flowers were measured in parallel. $x$ : control cuvette without flower

and the emission of $300 \mathrm{nmol}$ methyl benzoate $\mathrm{g}^{-1}$ fresh weight $\mathrm{h}^{-1}$ at the peak of scent emission in petunia corollas has been assumed to be supplied by a typical SAM pool of 0.3-30.0 $\mathrm{nmol} \mathrm{g}^{-1}$ fresh weight (Negre et al. 2003; Schuurink et al. 2006). Our analysis of $N$. suaveolens flowers revealed SAM levels between 10 and $50 \mathrm{nmol} \mathrm{g}^{-1}$ fresh weight, which is in the range of reported SAM levels in plant tissue. During the time of methyl benzoate emission in $N$. suaveolens flowers, the SAM levels decrease to approximately $10-20 \mathrm{nmol} \mathrm{g}^{-1}$ fresh weight, whereas after the transition from night to day, maximum levels of about $50 \mathrm{nmol} \mathrm{g}^{-1}$ fresh weight are reached. This result suggests a link between the altered floral SAM content and the SAMconsuming reactions, which is further supported by the observation that (1) a decrease of methyl benzoate emission from snapdragon after pollination can be related to a decrease of the SAM/SAH ratio, (2) a relationship between the regulation of the shikimate pathway, the benzenoid pathway and the SAM cycle exists, because the genes of all three pathways are transcriptionally upregulated prior to benzenoid emission, and (3) the downregulation of the R2R3-type MYB transcription factor odorant1 in transgenic petunia also suppresses SAM synthetase (Negre et al. 2003; Verdonk et al. 2003, 2005, respectively).

Since SAM is a ubiquitous compound of all living cells/ organisms it was expected that the housekeeping genes methionine synthase (MS) and SAM synthetase (SAMS) are constitutively expressed in all tissues and during various developmental stages. However, Northern blot analysis of the SAM cycle genes showed highest transcript levels in petal tissue of $N$. suaveolens, one-third of these transcript levels in stems and style/stigma, and extremely low levels in other floral tissues, leaves and roots (Fig. 3). A similar expression profile has been found for methionine synthase (StMS1) from potato (Zeh et al. 2002). In contrast, in A. thaliana and Pinus contorta, SAM synthetase is highly expressed in roots and stems and transcripts are not 
detectable in the inflorescences (Peleman et al. 1989; Lindroth et al. 2001). The discrepancy of expression profiles can be explained on the basis of the different regulation of expression (1) in different plant species, (2) throughout the development of tissues, and (3) at different time points during the day. For example, significant nocturnal oscillations of NsSAMS1 and NsMS1 transcripts were observed in $N$. suaveolens flowers (Fig. 4), while reverse patterns have been seen in the leaves of $N$. suaveolens and A. thaliana, viz. low levels of SAM synthetase and methionine synthase at the light to dark transition (Roeder and Piechulla unpublished results; Bläsing et al. 2005).

Different expression patterns might also be the result of the presence of gene families. Although only single genes from $N$. suaveolens flowers have been isolated, gene families of SAM synthetase and methionine synthase are known to exist in plants. Our expression experiments, however, were not designed to differentiate between the levels of individual genes. In A. thaliana, three methionine synthase genes have been investigated (AtMS1-3), each having a distinct expression profile: $A t \mathrm{MS} 1$ is expressed in all organs, most abundantly in flowers and little in roots; AtMS2 is less expressed than $A t \mathrm{MS} 1$ and low transcript levels are found in flowers; AtMS3 shows overall low expression levels, other than in seeds (Ravanel et al. 2004). Distinct expression profiles were also found for the three SAM synthetases from Catharanthus roseus and for the two root-specific genes from P. contorta (Schröder et al. 1997; Lindroth et al. 2001). CrSAMS3 exhibits a strong transient increase during the first 3 days of growth in cell culture, whereas $C r$ SAMS2 reaches its optimum later, and $\mathrm{CrSAMS1}$ peaks between the 3rd and 9th day. In addition, cellular localization also has to be considered for understanding the complete regulation of the SAM cycle. The existence of SAM cycle isoenzymes (Schröder et al. 1994; Eichel et al. 1995; Schröder et al. 1997; Eckermann et al. 2000) and carrier-dependent transport systems between the compartments, proposes SAM transport from the cytosol into chloroplasts and a conversion therein via SAH and via homocysteine to methionine in order to supply the chloroplast with this essential amino acid (Ravanel et al. 2004). In the cytosol, methionine serves as a precursor for protein synthesis and for SAM regeneration. $A t \mathrm{MS} 1$ and 2 are cytosolic proteins, whereas AtMS3 contains a functional plastid target sequence and can be isolated from chloroplasts (Ravanel et al. 2004). The two cDNAs of the SAM cycle isolated from $N$. suaveolens flower tissue appear to be cytosolic enzymes, since no target signals have been found at the $N$-terminus of the proteins.

$S^{\prime}$ adenosyl-L-methionine (SAM) is not only a transmethylation agent but also a precursor for polyamines, nicotianamine, biotin and ethylene. Ethylene is a gaseous plant hormone involved in many physiological processes including fruit ripening, abcission and senescence processes in flowers (Sarafini-Fracassini et al. 2002; Dexter et al. 2008). Ethylene that is emitted from the flower coincides with fertilisation, e.g. a burst of ethylene is produced from the stigma/style within $2-4 \mathrm{~h}$ after pollination, followed by a sustained autocatalytic ethylene production peaking $24 \mathrm{~h}$ after pollination, and this ethylene peak initiates the processes of senescence (Hoekstra and Weges 1986; van Doorn 1997; Wilkinson et al. 1997). Pollen tube growth and volatile synthesis are also synchronised by ethylene (Hoekstra and Weges 1986; Holden et al. 2003; Underwood et al. 2005). In individual $N$. suaveolens flowers, we have observed a single ethylene burst at the end of the life span of the flower (Fig. 5), but no rhythmic emission, which might have been expected from the NsACO mRNA oscillations (Fig. 4). During our experiments, self-fertilisation of the $N$. suaveolens flowers occurred, which might cause the ethylene bursts in the individual flowers. Peak levels of ethylene emission of $4.5 \mathrm{nl}$ per flower $\mathrm{h}^{-1}\left(45 \mathrm{nl} \mathrm{g}^{-1}\right.$ fresh weight $\mathrm{h}^{-1}$ ) were reached by $N$. suaveolens flowers, which is in the range of carnation and tobacco flowers $\left(25 \mathrm{nl} \mathrm{g}^{-1}\right.$ fresh weight $\mathrm{h}^{-1}$, Shibuya et al. 2000; De Martinis et al. 2002) and lower than from tomato (150$300 \mathrm{nl} \mathrm{g}^{-1}$ fresh weight $\mathrm{h}^{-1}$, Llop-Tous et al. 2000). Other plants such as Alstroemeria peruviana and tulips produce only very little amounts $\left(0.15 \mathrm{nl}\right.$ per flower $\mathrm{h}^{-1}$ ) (Wagstaff et al. 2005; Sexton et al. 2000, respectively). Interestingly, no dramatic decrease of SAM levels in 5- or 6-day-old $N$. suaveolens flowers is visible during the rapid burst of ethylene emission. Therefore, our results suggest that only small amounts of the SAM pool contribute to the ethylene burst. Whether higher ethylene emission as in tomato would reflect changes in SAM levels remains to be investigated.

Acknowledgments The authors thank Rita Heese and Claudia Dinse (University of Rostock) for their technical assistance, Dr. Uta Effmert for the construction of the phylogenetic trees and figure preparation, and Sandra Saschenbrecker for many RNA samples. This project was financially supported by the EU-FP6-Infrastructures-5 programm (project FP6-026183, Life Science Trace Gas Facility) to $\mathrm{FvH} / \mathrm{SC}$ and the DFG to BP.

Open Access This article is distributed under the terms of the Creative Commons Attribution Noncommercial License which permits any noncommercial use, distribution, and reproduction in any medium, provided the original author(s) and source are credited.

\section{References}

Altschul SF, Gish W, Miller W, Byers EW, Lipman DJ (1990) Basic local alignment search tool. J Mol Biol 215:402-410

Bläsing OE, Gibon Y, Günther M, Höhne M, Morcuende R, Osuna D, Thimm O, Usadel B, Scheible WR, Stitt M (2005) Sugars and circadian regulation make major contributions to the global 
regulation of diurnal gene expression in Arabidopsis. Plant Cell 17:3257-3281. doi:10.1105/tpc.105.035261

Bürstenbinder K, Rzewuski G, Wirtz M, Hell R, Sauter M (2007) The role of methionine recycling for ethylene synthesis in Arabidopsis. Plant J 49:238-249. doi:10.1111/j.1365-313X.2006.02942.x

Chang S, Puryear J, Cainey J (1993) A simple and efficient method for isolating RNA from pine trees. Plant Mol Biol Rep 11:113116. doi:10.1007/BF02670468

Cheng SH, Seemann JR (1998) Extraction and purification of RNA from plant tissue enriched in polysaccharides. Meth Mol Biol 268:23016-23024

Cristescu SM, De Martinis D, Te Lintel Hekkert S, Parker DH, Harren FJM (2002) Ethylene production by Botrytis cinerea in vitro and in tomatoes. App Envir Microbiol 68:5324-5350

De Martinis D, Cotti G, Te Lintel Hekkert S, Harren FJM, Mariani C (2002) Ethylene response to pollen tube growth in Nicotiana tabacum flower. Planta 214:806-812. doi:10.1007/s00425-0010684-2

Dexter RJ, Verdonk JC, Underwood BA, Shibuya K, Schmelz EA, Clark DG (2008) Tissue-specific PhBPBT expression is differentially regulated in response to endogenous ethylene. J Exp Bot 59:609-618. doi:10.1093/jxb/erm337

Dunkel M, Schmidt U, Struck S, Berger L, Gruening B, Hossbach J, Jaeger IS, Effmert U, Piechulla B, Eriksson R, Knudsen J, Preissner R (2009) SuperScent-a database of flavors and scents. Nucl Acid Res 37:D291-294. doi:10.1093/nar/gkn695

Eckermann C, Eichel J, Schröder J (2000) Plant methionine synthase: new insights into properties and expression. Biol Chem 381:695-703. doi:10.1515/BC.2000.090

Effmert U, Saschenbrecker S, Ross J, Negre F, Fraser CM, Noel JP, Dudareva N, Piechulla B (2005) Floral benzenoid carboxyl methyltransferases: From in vitro to in planta function. Phytochem 6:1211-1230

Effmert U, Dinse C, Piechulla B (2008) Influence of green leaf herbivory by Manduca sexta on floral volatile emission by Nicotiana suaveolens. Plant Physiol 146:1996-2007. doi:10.1104/ pp.107.112326

Eichel J, Gonzalez JC, Hotze M, Matthews RG, Schröder J (1995) Vitamin-B12-independent methionine synthase from a higher plant (Catharanthus roseus). Molecular characterization, regulation, heterologous expression, and enzyme properties. Eur J Biochem 230:1053-1058

Giovanelli J, Mudd SH, Datko AH (1985) Quantitative analysis of pathways of methionine metabolism and their regulation in Lemna. Plant Physiol 78:555-560. doi:10.1104/pp.78.3.555

Haink G, Deussen A (2003) Liquid chromatography method for the analysis of adenosine compounds. J Chrom Anal Technol Biomedl Life Sci 784:189-193. doi:10.1016/S1570-0232(02)007 $52-3$

Harren FJ, Reuss J (1997) Photoacoustic spectroscopy. In: Encyclopedia of applied physics, vol 19. Wiley-VHC, Weinheim

Hoekstra FA, Weges R (1986) Lack of control by early pistillate ethylene on the accelerated wilting of Petunia hybrida flowers. Plant Physiol 80:403-408. doi:10.1104/pp.80.2.403

Holden MJ, Marty JA, Singh-Cundy A (2003) Pollination-induced ethylene promoters the early phase of pollen tube growth in Petunia inflata. J Plant Physiol 160:261-269. doi:10.1078/ 0176-1617-00929

Horikawa S, Sasuga J, Shimizu K, Ozasa H, Tsukada K (1990) Molecular cloning and nucleotide sequence of cDNA encoding the rat kidney $S^{\prime}$ adenosyl methionine synthase. J Biol Chem 265: 13683-13686

Kagan RM, Clarke S (1994) Widespread occurrence of three sequence motifs in diverse $S^{\prime}$ adenosylmethionine dependent methyltransferases suggests a common structure for these enzymes. Arch Biochem Biophys 310:417-427. doi:10.1006/abbi.1994.1187
Kapteyn J, Qualley AV, Xie Z, Fridman E, Dudareva N, Gang DR (2007) Evolution of cinnamate/p-coumarate carboxyl methyltransferases and their role in the biosynthesis of methylcinnamate. Plant Cell 19:3212-3229. doi:10.1105/tpc.107.054155

Knudsen JT, Eriksson R, Gershenzon J, Stahl B (2006) Diversity and distribution of floral scent. Bot Rev 72:1-120. doi:10.1663/00068101(2006)72[1:DADOFS]2.0.CO;2

Lavid N, Wang J, Shalit M, Gutterman I, Bar E, Beuerlein T, Weiss D, Vainstein A, Pichersky E, Lewinsohn E (2002) $O$-methyltransferases involved in the biosynthesis of volatile phenol derivatives in rose petals. Plant Physiol 129:1899-1907. doi:10.1104/pp.00 5330

Lindroth AM, Saarikoski P, Flygh G, Clapham D, Grönroos R, Thelander M, Ronne H, von Arnold S (2001) Two $S^{\prime}$ adenosylmethionine synthetase-encoding genes differentially expressed during adventitious root development in Pinus contorta. Plant Mol Biol 46:335-346. doi:10.1023/A:1010637012528

Llop-Tous I, Barry CS, Grierson D (2000) Regulation of ethylene biosynthesis in response to pollination in tomato flowers. Plant Physiol 123:971-978. doi:10.1104/pp.123.3.971

Negre F, Kish CM, Boatright J, Underwood B, Shibuya K, Wagner C, Clark DG, Dudareva N (2003) Regulation of methyl benzoate emission after pollination in snapdragon and petunia flowers. Plant Cell 15:1-16. doi:10.1105/tpc.016766

Noel JP, Dixon RA, Pichersky E, Zubieta C, Ferrer JL (2003) Structural, functional, and evolutionary basis for methylation of plant small molecules. In: Romeo JT (ed) Recent advances in phytochemistry, vol 37. Elsevier Science \& Technology, Oxford, pp $37-58$

Pare PW, Tumlinson JH (1999) Plant volatiles as a defense against insect herbivores. Plant Physiol 121:325-331. doi:10.1104/pp. 121.2.325

Peleman J, Boerjan W, Engler G, Seurinck J, Botterman J, Alliotte T, van Montagu M, Inze D (1989) Strong cellular preference in the expression of a housekeeping gene of Arabidopsis thaliana encoding $S^{\prime}$-adenosylmethionine synthetase. Plant Cell 1:81-93

Piechulla B, Pott MB (2003) Plant scents-mediators of inter-and intraorganismic communication. Planta 217:687-689. doi:10.1007/ s00425-003-1047-y

Pott MB, Hippauf F, Saschenbrecker S, Chen F, Ross J, Kiefer I, Slusarenko A, Noel JP, Pichersky E, Effmert U, Piechulla B (2004) Biochemical and structural characterization of benzenoid carboxyl methyltransferases involved in floral scent production in Stephanotis floribunda and Nicotiana suaveolens. Plant Physiol 135:1946-1955. doi:10.1104/pp.104.041806

Ravanel S, Gakiere B, Job D, Douce R (1998) The specific features of methionine biosynthesis and metabolism in plants. Proc Nat Acad Sci USA 95:7805-7812. doi:10.1073/pnas.95.13.7805

Ravanel S, Block MA, Rippert P, Jabrin S, Curien G, Rebeille F, Douce R (2004) Methionine metabolism in plant: Chloroplasts are autonomous for de novo methionine synthesis and can import $S^{\prime}$ adenosyl-methionine from the cytosol. J Biol Chem 279: 22548-22557. doi:10.1074/jbc.M313250200

Rzewuski G, Cornell KA, Rooney L, Bürstenbinder K, Wirtz M, Hell R, Sauter M (2007) OsMTN encodes a 5'-methylthioadenosine nucleosidase that is up-regulated during submergence-induced ethylene synthesis in rice (Oryza sativa L.). J Exp Bot 58:15051514. doi:10.1093/jxb/erm014

Sarafini-Fracassini D, del Duca S, Monti F, Poli F, Sacchetti G, Bregoli AM, Biondi S, Della Mea M (2002) Transglutaminase activity during senescence and programmed cell death in the corolla of tabacco (Nicotiana tabaccum) flowers. Cell Death Diff 9:309-321. doi:10.1038/sj.cdd.4400954

Schröder G, Waitz A, Hotze M, Schröder J (1994) cDNA for $S^{\prime}$ adenosyl-L-homocysteine hydrolase from Catharanthus roseus. Plant Physiol 104:1099-1100. doi:10.1104/pp.104.3.1099 
Schröder G, Eichel J, Breinig S, Schröder J (1997) Three differentially expressed $S^{\prime}$-adenosyl-methionine synthetase from Catharanthus roseus: molecular and functional characterization. Plant Mol Biol 33:211-222. doi:10.1023/A:1005711720930

Schuurink RC, Haring MA, Clark DG (2006) Regulation of volatile benzenoid biosynthesis in petunia flowers. TIPS 11:20-25. doi: 10.1016/j.tplants.2005.09.009

Seo HS, Song JT, Cheong JJ, Lee YH, Lee YW, Hwang J, Lee JS (2001) Jasmonic acid carboxyl methyltransferase: a key enzyme for jasmonate-regulated plant responses. Proc Nat Acad Sci USA 98:4788-4793. doi:10.1073/pnas.081557298

Sexton R, Laird G, van Doorn W (2000) Lack of ethylene involvement in tulip tepal abscission. Physiol Plantarum 108: 321-329. doi:10.1034/j.1399-3054.2000.108003321.x

Shibuya K, Yoshioka T, Hashiba T, Satoh S (2000) Role of the gynoecium in natural senescence of carnation (Dianthus caryophyllus L.) flowers. J Exp Bot 51:2067-2073. doi:10.1093/ jexbot/51.353.2067

Te Lintel Hekkert S, Staal MJ, Nabben RHM, Zuckermann H, Persijn S, Stal LJ, Voesenek LACJ, Harren FJM, Reiss J, Parker DH (1998) Laser photoacoustic trace detection, an extremely sensitive technique applied in biological research. Instrum Sci Technol 26:157-175. doi:10.1080/10739149808002690

Underwood BA, Tieman DM, Shibuyam K, Dexter RJ, Loucasm HM, Simkin AJ, Sims CA, Schmelz EA, Klee HJ, Clark DG (2005) Ethylene-regulated floral volatile synthesis in Petunia corollas. Plant Physiol 138:255-266. doi:10.1104/pp.104.051144

Van Doorn WG (1997) Effects of pollination on floral attraction and longevity. J Exp Bot 48:1615-1622

Verdonk JC, Ric de Vos CH, Verhoeven HA, Haring MA, van Tunen AJ, Schuurink RC (2003) Regulation of floral scent production in Petunia revealed by targeted metabolomics. Phytochem 62:997-1008. doi:10.1016/S0031-9422(02)00707-0
Verdonk JC, Haring MA, van der Hejden R, van Runen AJ, Schuurink RC (2005) ODORANT1 regulates fragrance biosynthesis in petunia flowers. Plant Cell 17:1612-1624. doi:10.1105/tpc.104. 028837

Wagstaff C, Chanasut U, Harren FJ, Laarhoven LJ, Thomas B, Rogers HJ, Stead AD (2005) Ethylene and flower longevity in Alstroemeria: relationship between tepal senescence, absission and ethylene biosynthesis. J Exp Bot 56:1007-1016. doi:10.1093/jxb/eri094

Wang J, Dudareva N, Bhakta S, Raguso RA, Pichersky E (1997) Floral scent production in Clarkia breweri (Onagraceae): II. Localization and developmental modulation of the enzyme $S^{\prime}$ adenosyl-Lmethionine:(iso)eugenol $O^{\prime}$-methyltransferase and phenylpropanoid emission. Plant Physiol 114:213-221. doi:10.1104/pp.114. 1.213

Wein M, Lavid N, Lunkenbein S, Lewinsohn E, Schwab W, Kaldenhoff $\mathrm{R}$ (2002) Isolation, cloning and expression of a multifunctional $O^{\prime}$-methyltransferase capable of forming 2, 5-dimethyl-4-methoxy-3(2H)-furanone, one of the key aroma compounds in strawberry fruits. Plant J 31:755-765. doi:10.1046/j.1365-313X.2002. 01396.x

Wilkinson JQ, Lanahan MB, Clark DG, Bleecker AB, Chang C, Meyerowitz EM, Klee HJ (1997) A dominant mutant receptor from Arabidopsis confers ethylene intensitivity in heterologous plants. Nature Biotech 15:444-447. doi:10.1038/nbt0597-444

Yang Y, Yuan JS, Ross J, Noel JP, Pichersky E, Chen F (2005) An Arabidospsis thaliana methyltransferase capable of methylating farnesoic acid. Arch Biochem Biophys 448:1-2

Zeh M, Leggewie G, Hoefgen R, Hesse H (2002) Cloning and characterization of a cDNA encoding a cobalamin-independent methionine synthase from potato (Solanum tuberosum L.). Plant Mol Biol 48:255-265. doi:10.1023/A:1013333303554 